\title{
PEMBANGUNAN INFRASTRUKTUR VOICE OVER INTERNET PROTOCOL DI ORGANISASI PERANGKAT DAERAH BOYOLALI MENGGUNAKAN SERVER ELASTIX
}

\author{
Maftufin Exsan \\ Program Studi Informatika Universitas Muhammadiyah Surakarta (UMS) \\ Surakarta, Indonesia 1200140123@student.ums.ac.id \\ Umi Fadlilah \\ Program Studi Teknik Elektro Universitas Muhammadiyah Surakarta (UMS) \\ Surakarta, Indonesia Umi.Fadlilah@ums.ac.id
}

\begin{abstract}
Abstrak - Perkembangan teknologi informasi dan komunikasi yang semakin maju, didukung dengan jaringan internet yang semakin sering digunakan dalam kehidupan sehari-hari serta pentingnya komunikasi dalam sebuah lingkungan pemerintahan, maka dalam penelitian ini penulis membangun infrastruktur jaringan Voice over Internet Protocol (VoIP) di Organisasi Perangkat Daerah Boyolali (OPD Boyolali) menggunakan Server Elastix. Teknologi ini mampu menyediakan komunikasi yang berjalan pada jaringan internet yang tentunya lebih hemat jika dibandingkan harus menggunakan operator telepon ataupun berlangganan jasa telepon rumah. Hasil penelitian ini berupa jaringan VoIP yang dapat diakses oleh seluruh OPD Boyolali. Hasil pengujian yang lakukan menggunakan aplikasi Wireshark menunjukkan bahwa jaringan VoIP ini memiliki kualitas yang bagus, sehingga komunikasi yang berlangsung dapat berjalan dengan lancar.
\end{abstract}

Kata Kunci - OPD Boyolali, Server Elastix, VoIP, Wireshark

\section{PENDAHULUAN}

Perkembangan teknologi informasi yang pesat membawa perubahan besar pada dunia telekomunikasi. Dengan didukung perkembangan teknologi internet yang melaju dengan pesatnya, menghasilkan teknologiteknologi baru yang sangat membantu kehidupan manusia dalam hal komunikasi. Salah satunya adalah teknologi telepon suara yang menggunkan jaringan internet. Teknologi ini dikenal dengan nama Voice over Internet Protocol (VoIP). Menurut M. Iskandarsyah (2003), Voice over Internet Protocol (VoIP) adalah teknologi yang mampu melewatkan trafik suara, video dan data yang berbentuk paket melalui jaringan IP. Jaringan IP sendiri merupakan jaringan komunikasi data yang berbasis packet-switch, jadi dalam bertelepon menggunakan jaringan IP atau Internet. Penggunaan VoIP semakin banyak digemari karena tidak memerlukan pulsa atau biaya yang cukup besar. Hal tersebut dikarenakan teknologi VoIP berjalan pada jaringan internet.

Komunikasi merupakan suatu hal yang penting bagi manusia untuk saling bertukar informasi. Terlebih pada komunikasi antar-instansi dalam satuan perangkat kerja pada suatu daerah untuk meningkatkan pelayanan, mutu dan kinerjanya agar menjadi lebih cepat dan efisien. Organisasi Perangkat Daerah Boyolali (OPD Boyolali) membutuhkan alat telekomunikasi untuk melakukan pertukaran informasi ataupun berkoordinasi antar instansi.

Pemerintah Kabupaten Boyolali menunjuk PT. Lintas Data Prima (LDP) sebagai perusahaan layanan internet untuk membangun jaringan telepon VoIP pada OPD Boyolali. LDP merupakan sebuah perusahaan penyelenggara jasa telekomunikasi terkemuka khususnya di Surakarta dan Indonesia pada umumnya, 
beroperasi secara penuh sejak akhir tahun 2008 untuk membangun dan menerapkan jasa dan produk berbasis IP, internet dan multimedia di Indonesia. LDP melayani empat segmen pelanggan, yaitu korporasi (besar, menengah, dan kecil), pemerintah, institusi, residensial dan perorangan. Pada tugas akhir ini, penulis bekerja sama dengan LDP untuk membangun jaringan telepon VoIP tersebut.

Saputra \& Lestari. (2014) Melakukan penelitian dengan judul Analisa dan Perancangan Voice over Internet Protocol (VoIP) Menggunakan Teknologi Open Source pada Pusat Teknologi Informasi dan Pangkalan Data UIN Suska Riau, alat yang digunakan yaitu IP komputer yang terhubung ke jaringan internet sebagai client, komputer server, headset, software softphone $3 \mathrm{CX}$ Phone VoIP berbasis SIP, handphone yang memiliki sistem operasi android dan bandwidth yang memadai. Server VoIP menggunakan sistem operasi linux debian lenny, lalu untuk masing-masing komputer client diinstal software softphone 3CX Phone. Penggunaan teknologi VoIP ini dapat meningkatkan efisiensi biaya operasional instansi serta dapat memaksimalkan PC yang ada untuk difungsikan sebagai softphone, Komunikasi VoIP yang dapat dilakukan yaitu antar PC ke PC, Hp Android ke PC, PC ke Hp android dan dari $\mathrm{Hp}$ androi ke $\mathrm{Hp}$ android.

Prasetyo. (2015) melakukan penelitiannya yang berjudul Implementasi VoIP (Voice over Internet Protokol) pada Jaringan LAN (Local Area Network) Dinas Kesehatan Kabupaten Musi Banyuasin. Media komunikasi ini dibangun menggunakan Server Briker, aplikasi Softphone X-lite dan aplikasi CsipSimple. Penerapan VoIP pada Dinas Kesehatan Kabupaten Musi Banyuasin ini membuat pegawai dan staff Dinas Kesehatan Kabupaten Musi Banyuasin dalam berkomunikasi dapat melalui media teks, media suara ataupun video. Biayanya relatif terjangkau sehingga dapat meningkatkan koordinasi antar bagian dan informasi yang disampaikan lebih jelas dan cepat.
Oladipo, Madu, \& Okoro. (2015) dengan penelitiannya yang berjudul Re-Engineering Campus-Wide Internet Telephony Using Voice over Internet Protocol, mereka menggunakan aplikasi Cisco Packet Tracer yang digunakan untuk melakukan simulasi komunikasi VoIP, cara kerja pada penelitian ini yaitu Cisco Packet Tracer dikonfigurasi untuk menjalankan beberapa sesi simulasi spesifikasi yang dikembangkan. Hasil simulasi menunjukkan bahwa VoIP dapat dengan sukses digunakan untuk menyediakan secara fleksibel, layanan berbasis data tambahan pada telepon di seluruh kampus melalui penggabungan fasilitas telepon dan teknologi informasi.

Bestian \& Rakhmadi. (2011) melakukan penelitian yang berjudul Analisa Kinerja Voip dan Video Conference Menggunakan Briker Softswitch pada Jaringan Universitas Muhammadiyah Surakarta. Penelitian ini menggunakan server briker dan laptop dengan dilengkapi aplikasi softphone sebagai client dan aplikasi wireshark untuk melakukan analisis mencari delay, jitter, throughput dan packet loss, yang kemudian bisa diimplementasikan pada jaringan Universitas Muhammadiyah Surakarta sebagai komunikasi alternatif intra kampus.

Dalam penelitian-penelitian sebelumnya, jaringan VoIP hanya diaplikasikan pada lingkup yang relatif kecil. Bahkan ada pula yang hanya melakukan simulasi saja dan tidak di aplikasikan. Jaringan VoIP yang diaplikasikan pada suatu lingkup yang luas akan lebih baik dan dapat membantu komunikasi pada lingkup tersebut. Saat ini komunikasi menggunakan jasa telepon umum atau Public Switched Telephone Network (PSTN) memang sudah menjadi hal yang biasa pada kehidupan masyarakat, namun penggunaan teknologi VoIP memiliki keunggulan dengan kemampuan untuk melakukan panggilan video, jadi tidak hanya digunakan untuk panggilan suara saja. Jaringan VoIP ini juga dapat diaplikasikan 
pada Smartphone, sehingga pegawai pemerintahan dapat berkomunikasi dimanapun menggunakan Smartphonenya.

Diharapkan jaringan VoIP ini dapat membantu komunikasi antar instansi di lingkungan OPD Boyolali menjadi lebih baik lagi, dapat menghemat biaya komunikasi di setiap instansi serta dengan dibangunnya infrastruktur VoIP ini menjadikan suatu kebanggan bagi Pemerintah Boyolali karena memiliki media komunikasi tersendiri yang tidak dimiliki oleh daerah lain. Mungkin untuk sementara komunikasi menggunakan jasa telepon umum atau PSTN lebih banyak dikenal oleh masyarakat dan memiliki kualitas yang sedikit lebih baik, namun untuk kedepan jaringan VoIP ini pasti bisa mengalahkan kualitas jasa telepon umum atau PSTN yang ada dan masyarakat luas khususnya masyarakat Boyolali dapat lebih mengenal teknologi VoIP.

\section{METODE}

Metode yang digunakan dalam penelitian ini antara lain yaitu, observasi, wawancara, analisis kebutuhan, perancangan jaringan, implementasi dan pengujian.

\subsection{Observasi}

Observasi yaitu suatu metode yang dilakukan dengan cara melakukan pengamatan secara langsung terhadap objek penelitian dengan tujuan untuk memperoleh data-data yang dibutuhkan dalam penelitian.

\subsection{Wawancara}

Wawancara yaitu suatu cara untuk mendapatkan data-data yang dibutuhkan dengan cara bertanya langsung terhadap pihak yang bersangkutan. Disini, penulis melakukan wawancara terhadap pihak OPD Boyolali mengenai kebutuhan apa saja yang diperlukan dalam penelitian ini.

\subsection{Analisis Kebutuhan}

Tahap analisis kebutuhan yaitu penulis menganalisis kebutuhan apa saja yang diperlukan untuk melakukan penelitian ini.
Kebutuhan yang diperlukan yaitu alat dan bahan yang meliputi hardware dan software. Kebutuhan alat dan bahan yang dibutuhkan untuk membangun jaringan VoIP di OPD Boyolali akan dijelaskan pada Tabel 1 dan Tabel 2.

Tabel 1. Kebutuhan Hardware

\section{Hardware Keterangan}

Komputer

Server Elastix

Xeon Dual

Processor,

8GB RAM,

Harddisk

100GB

Video Phone komunikasi baik melalui

GXV3240 panggilan suara ataupun panggilan video

Telepon

Analog

Panasonic

KX-TS5

$05 \mathrm{MX}$

VoIP

Gateway

VIP-157S

ATA VoIP

172 Plus

Pesawat telepon untuk

komunikasi panggilan suara

pada jaringan VoIP

Perangkat untuk

menghubungkan jaringan

VoIP dengan telepon PSTN

Alat yang berfungsi untuk merubah sinyal analog menjadi digital.

Alat jaringan internet untuk

Router menghubungkan berbagai

network

Perangkat jaringan

komputer yang berfungsi

Switch

untuk menghubungkan

antar node

Tabel 2. Kebutuhan Software

Software

Keterangan

$\begin{array}{ll}\begin{array}{ll}\text { Sistem } \\ \text { Operasi }\end{array} & \begin{array}{l}\text { Sistem operasi open source } \\ \text { distro Linux }\end{array} \\ \text { Elastix } & \begin{array}{l}\text { Aplikasi untuk me-remote } \\ \text { Web Browser } \\ \text { server Elastix dan ATA } \\ \text { VoIP }\end{array}\end{array}$




\section{Wireshark \\ Versi 2.4.3 \\ Aplikasi untuk melakukan pengujian Quality of Service}

Tabel 1 adalah daftar kebutuhan Hardware. Hardware yang digunakan antara lain yaitu Komputer Server Elastix, Video Phone, Telepon Analog, VoIP Gateway, ATA VoIP dan Router. Sementara untuk tabel 2 adalah daftar software yang digunakan, yaitu Sistem Operasi Elastix, Browser dan Wireshark.

\subsection{Perancangan Jaringan}

Rancangan Jaringan dalam pembangunan jaringan VoIP di OPD Boyolali di jelaskan dalam topologi jaringan pada Gambar 1.

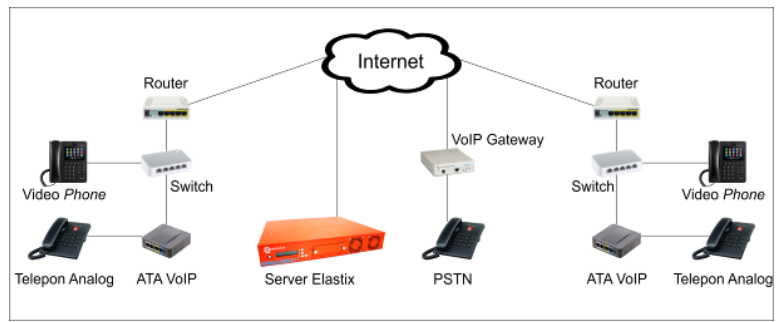

Gambar 1. Topologi Jaringan VoIP.

Gambar 1 menjelaskan topologi jaringan internet pada OPD Boyolali yang digunakan untuk membangun jaringan VoIP. Pada intinya, semua perangkat harus terhubung dengan jaringan internet, mulai dari server, VoIP Gateway, ATA VoIP dan Video Phone.

\subsection{Implementasi}

Semua data yang diperoleh akan diimplementasikan untuk membangun jaringan komunikasi dengan memanfaatkan jaringan internet yang menggunakan teknologi VoIP serta Elastik sebagai servernya, di OPD Boyolali. Pada pelaksanaan tugas akhir ini, instalasi jaringan VoIP dilakukan di 6 Kecamatan, yaitu Kecamatan Karanggede, Klego, Andong, Kemusu, Juwangi dan Wonosegoro.

\subsection{Pengujian}

Pengujian dilakukan setelah tahap implementasi selesai dikerjakan. Pengujian dilaksanakan dengan cara melakukan ping dari jaringan pada client menuju ke Server Elastik, mencoba menelepon antar client pada jaringan VoIP yang telah dibangun dan pengujian Quality of Service.

\section{HASIL DAN PEMBAHASAN}

\subsection{Implementasi}

Semua data yang diperoleh akan diimplementasikan untuk membangun jaringan komunikasi dengan memanfaatkan jaringan internet yang menggunakan teknologi VoIP serta Elastik sebagai servernya di OPD Boyolali. Pada pelaksanaan tugas akhir ini, instalasi jaringan VoIP dilakukan di 6 Kecamatan, yaitu Kecamatan Karanggede, Klego, Andong, Kemusu, Juwangi dan Wonosegoro.

\subsubsection{Instalasi Server Elastix}

Hal pertama yang dilakukan adalah dengan melakukan instalasi server menggunakan Sistem Operasi Elastix. Server Elastix menjadi kebutuhan paling penting dalam penelitian ini.

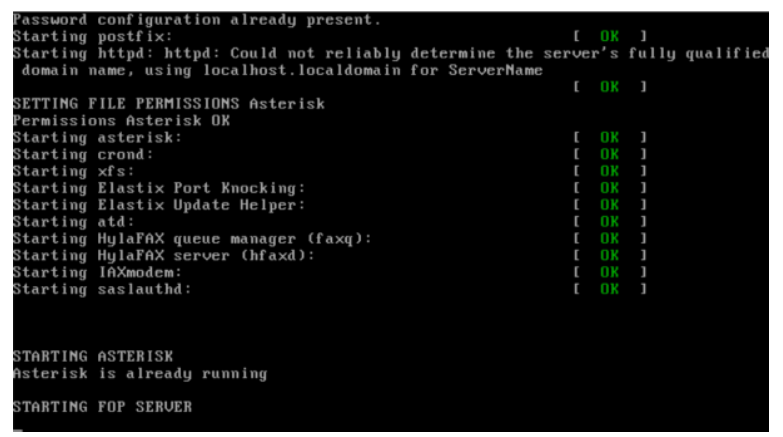

Gambar 2. Proses Instalasi Server Elastix

Gambar 2 merupakan proses instalasi Server Elastix dilakukan seperti saat menginstal sistem operasi distro linux lainnya pada umumnya. Setelah berhasil terinstal dan berhasil masuk pada Sistem Operasi Elastik, lalu mengatur IP Server Elastik yang nantinya IP tersebut akan digunakan untuk me-remote server dari komputer lain.

\subsubsection{Konfigurasi Server Elastik}

Setelah instalasi Server Elastix selesai, tahap berikutnya adalah dengan melakukan konfigurasi pada Server Elastix itu sendiri. 
Konfigurasi pertama dilakukan dengan membuat akun Extension.

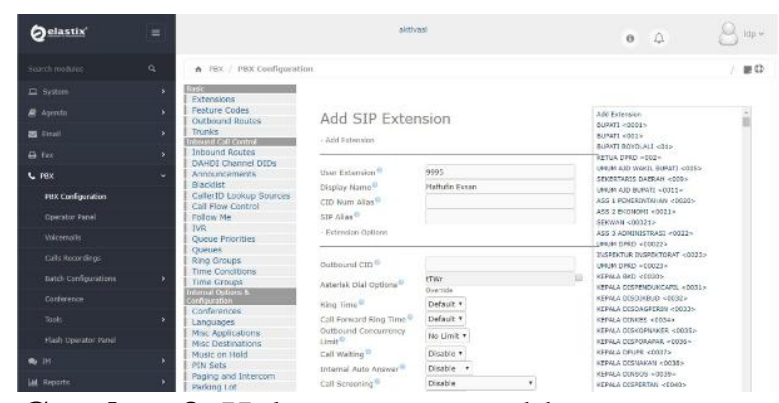

Gambar 3. Halaman memasukkan Extension

Gambar 3 merupakan konfigurasi SIP Extension pada Server Elastix dapat dilakukan dengan cara masuk ke halaman login server dengan menggunakan alamat domain server Elastix. Masuk ke menu PBX, lalu PBX Configuration. Pilih generic SIP Device kemudian submit. Kemudian masukkan user extension dan display name. Lalu masukkan pula secret atau passwordnya.

Setelah pembuatan extension selesai, tahap selanjutnya adalah membuat pengaturan pada outbond agar dapat melakukan panggilan dari jaringan VoIP ke nomor telepon umum.

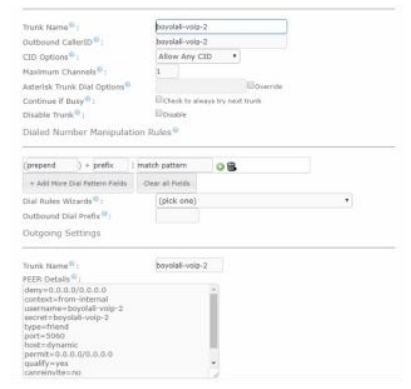

(a)

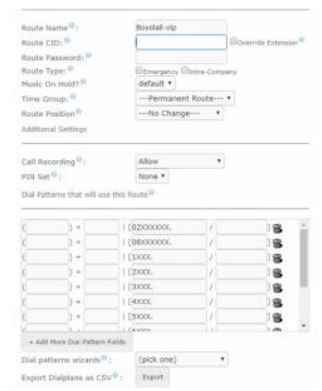

(b)
Gambar 4. Membuat trunk (a), membuat route (b)

Gambar 4 adalah cara konfigurasi outbond ini dilakukan dengan cara membuat trunks terlebih dahulu pada menu Trunks yang disesuaikan dengan pengaturan pada VoIP Gateway, kemudian menambah routes pada menu Outbond Routes.

\subsubsection{Konfigurasi VoIP Ggateway}

VoIP gateway disini memiliki fungsi agar dapat melakukan panggilan dari jaringan VoIP menuju ke nomor telepon umum.

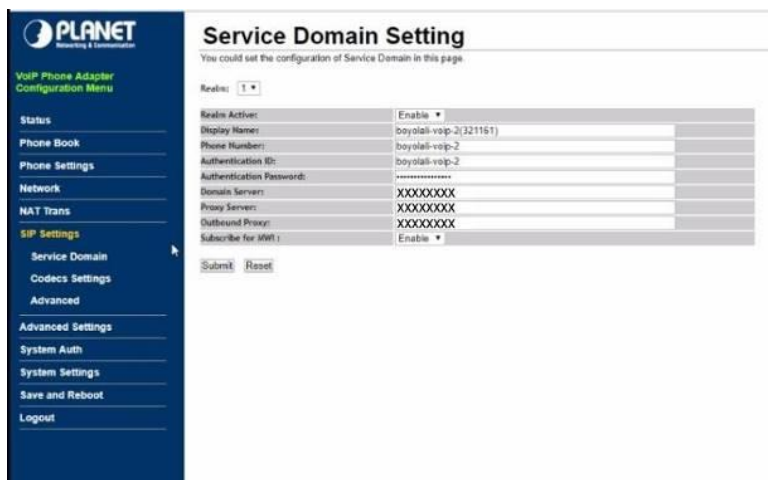

Gambar 5. Konfigurasi VoIP Gateway

Gambar 5 menunjukkan cara konfigurasi ini dilakukan pada menu Service Domain dengan memasukkan Display Name, Phone Number, Authentication ID, Authentication Password, Domain, Proxy Server dan Outbond Proxy.

\subsubsection{Konfigurasi ATA VoIP}

Tahap selanjutnya adalah mengkonfigurasi perangkat ATA VoIP yang berfungsi untuk merubah sinyal analog menjadi sinyal digital dan sebaliknya.

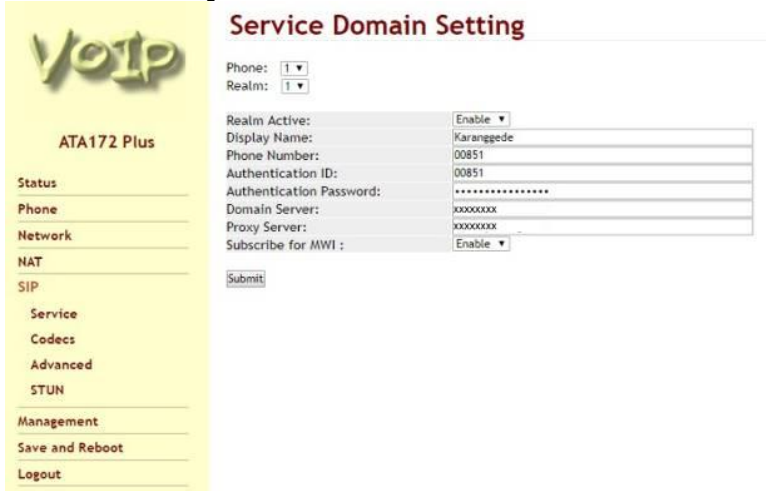

Gambar 6. Mengatur domain servis pada ATA VoIP

Gambar 6 merupakan konfigurasi ATA VoIP dapat dilakukan dengan cara masuk ke halaman ATA VoIP. Masukkan username password untuk login. Kemudian masuk ke menu SIP lalu Service. Atur service domain setting sesuai dengan Phone Number, Password, Domain Server dan Proxy Server sesuai dengan yang dibuat pada Server Elastix. Setelah diberi akses internet, maka ATA VoIP 
secara otomatis akan mendapatkan IP dan telepon analog dapat digunakan dengan menghubungkannya dengan ATA VoIP.

\subsubsection{Konfigurasi Video Phone}

Kemudian melakukan konfigurasi perangkat Video Phone agar dapat digunakan untuk berkomunikasi dalam jaringan VoIP. Selain digunakan untuk melakukan panggilan suara, perangkat ini juga mampu untuk melakukan panggilan video.

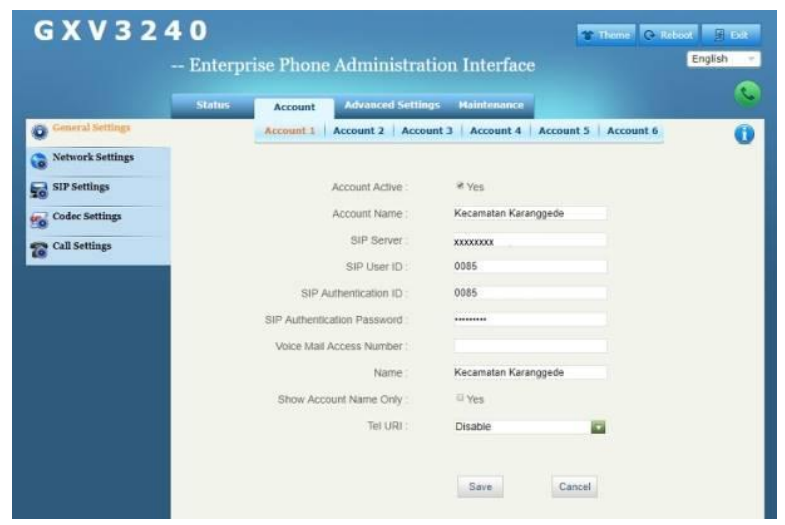

Gambar 7. Mengatur domain servis Video Phone

Gambar 7 adalah proses konfigurasi Video Phone. Konfigurasi Video Phone dapat dilakukan dengan cara masuk ke halaman telepon VoIP pada browser sesuai dengan IP yang didapatkan pada Video Phone. Masukkan username dan password. Kemudian masuk ke menu Account, lalu masukkan Account SIP sesuai dengan yang diatur pada Server Elastix. Seperti SIP Server, SIP User ID, SIP Authentication ID dan SIP Authentication Password. Setelah selesai, klik save lalu apply. Kemudian tunggu sampai proses apply selesai. Setelah selesai, hasil pengaturan dapat di lihat pada menu Status.

Hasil yang didapatkan dari penelitian ini berupa jaringan VoIP yang dapat digunakan untuk seluruh OPD Boyolali yang berfungsi untuk berkomunikasi antar instansi sehingga mempermudah dan mempercepat komunikasi dan dapat meningkatkan kualitas pelayanan publik serta sistem pelaporan kerja pada OPD Boyolali. Jaringan VoIP ini dapat diakses dari mana saja dengan syarat perangkat terkoneksi dengan internet dan telah memiliki akun SIP yang dibuat pada Server Elastix yang kemudian akun tersebut dikonfigurasikan pada perangkat ATA VoIP atau Video Phone agar dapat mengakses server VoIP. Jaringan VoIP ini juga mampu untuk menghemat pengeluran keuangan pada setiap OPD karena setiap OPD tidak perlu membayar biaya untuk berlangganan jasa telepon, karena jaringan VoIP ini berjalan pada jaringan internet, sehingga setiap OPD hanya perlu membayar biaya untuk berlangganan jasa internet saja.

Jaringan VoIP ini menjangkau sebanyak 48 Instansi di seluruh OPD Boyolali, mulai dari DPRD Boyolali, dinas-dinas, instansi-instansi pemerintahan, RSUD Pandan Aran hingga ke kecamatan-kecamatan seluruh Kabupaten Boyolali.

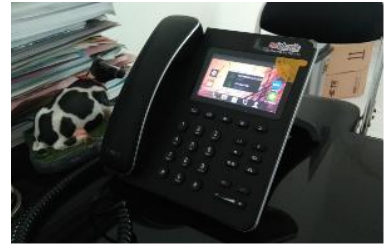

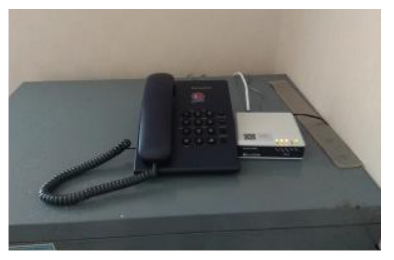

(b)
Gambar 8. Hasil instalasi Video Phone (a), hasil Instalasi Telepon Analog dan ATA VoIP

Gambar 8 adalah hasil implementasi Video Phone, Telepon Analog dan ATA VoIP di salah satu OPD Boyolali. Video phone diletakkan di meja kepala OPD, sementara telepon analog diletakkan sesuai dengan permintaan setiap OPD, bisa di meja sekretariat atupun di ruang penerimaan tamu.

\subsection{Pengujian}

\subsubsection{Pengujian Koneksi dari Client ke Server}

Pengujian ini dilakukan menggunakan tool command prompt dengan cara melakukan ping ke IP server Elastix dari jaringan yang digunakan oleh client. Hasil dari pengujian ini dipaparkan pada tabel 3 . 
Tabel 3. Hasil pengujian koneksi dari client ke server.

\begin{tabular}{lll}
\hline No & SIP Client & Hasil Pengujian \\
\hline 1 & SIP 0083 & Berhasil \\
2 & SIP 0084 & Berhasil \\
3 & SIP 0085 & Gagal \\
4 & SIP 0086 & Berhasil \\
5 & SIP 0087 & Berhasil \\
6 & SIP 0088 & Berhasil \\
\hline
\end{tabular}

Tabel 3 menunjukkan hasil pengujian yang melibatkan 6 client, terdapat satu client yang gagal melakukan ping ke server. Hal tersebut dikarenakan pada saat instalasi perangkat pada client SIP 0085 kondisi internet sedang mengalami gangguan, sehingga tidak dapat terkoneksi ke internet.

\subsubsection{Pengujian Panggilan Antar Client} Pengujian ini dilakukan dengan cara melakukan panggilan telepon langsung dari satu client ke client lain. Tujuan pengujian ini untuk melihat apakah perangkat yang di instalasi telah dapat digunakan untuk berkomunikasi atau belum.

Tabel 4. Hasil pengujian panggilan antar client

\begin{tabular}{llll}
$\begin{array}{c}\text { Pengujian } \\
\text { Ke }\end{array}$ & Dari SIP & Ke SIP & Hasil \\
\hline 1 & 0083 & 00831 & Gagal \\
2 & 0084 & 00841 & Berhasil \\
3 & 0085 & 00851 & Gagal \\
4 & 0086 & 00861 & Berhasil \\
5 & 0087 & 00871 & Berhasil \\
6 & 0088 & 00881 & Berhasil \\
\hline
\end{tabular}

Tabel 4 adalah hasil pengujian panggilan antar client. Pengujian panggilan dari SIP 0083 menuju ke SIP 00831 gagal dilakukan karena terjadi kesalahan pada password yang dimasukkan pada perangkat ATA VoIP yang digunakan oleh client dengan SIP 00831, password yang dimasukkan pada perangkat ATA VoIP tidak sesuai dengan password yang dibuat pada server, sehingga akun SIP 00831 tidak terdaftar pada Server Elastix. Panggilan dari SIP 0085 ke SIP 00851 juga mengalami kegagalan karena kondisi internet pada kedua client tersebut sedang bermasalah, sehingga client tidak dapat terhubung ke internet.

\subsubsection{Pengujian Quality of Service}

Quality of Service adalah parameter yang digunakan untuk menentukan kualitas layanan VoIP. Kualitas ini tergantung dari beberapa parameter, seperti delay, jitter, packet loss dan throughput.

Total waktu tunda dalam suatu pemrosesan data yang disebabkan oleh proses pengiriman dari pengirim atau sumber kepada penerima atau tujuan disebut dengan delay. Jitter adalah variasi dari delay yang diakibatkan oleh perbedaan selang waktu kedatangan antar paket. Packet loss adalah tidak tercapainya pengiriman paket dari pengirim kepada tujuan sehingga paket tidak dapat diterima oleh tujuan yang seharusnya menerima paket tersebut. Throughput adalah paket yang berhasil dikirimkan dalam satu satuan waktu.

Tabel 5. Parameter delay berdasarkan European Telecommunications Standards Institute (ETSI).

\begin{tabular}{ll}
\hline \multicolumn{1}{c}{ Delay } & \multicolumn{1}{c}{ Kualitas } \\
\hline$<150 \mathrm{~ms}$ & Best \\
$150 \mathrm{~ms}-249 \mathrm{~ms}$ & High \\
$250 \mathrm{~ms}-349 \mathrm{~ms}$ & Medium \\
$350 \mathrm{~ms}-449 \mathrm{~ms}$ & Low \\
\hline
\end{tabular}

Tabel 6. Standar Jitter dan Packet Loss untuk VoIP

\begin{tabular}{ccl}
\multicolumn{1}{c}{ Jitter } & $\begin{array}{c}\text { Packet } \\
\text { Loss }\end{array}$ & \multicolumn{1}{c}{ Kualitas } \\
\hline 0ms - 20ms & $0-0,5 \%$ & Good/ Baik \\
$20 \mathrm{~ms}-50 \mathrm{~ms}$ & $0,5-1,5 \%$ & $\begin{array}{l}\text { Acceptable/ } \\
\text { dapat diterima }\end{array}$ \\
$>50 \mathrm{~ms}$ & $>1,5 \%$ & Poor/ buruk \\
\hline
\end{tabular}

Tabel 5 merupakan parameter delay berdasarkan ETSI, sedangkan tabel 6 adalah standar jitter dan packet loss yang di 
kemukakan oleh Nurhayati (2010). Pengujian Quality of Service ini meliputi beberapa pengujian, diantaranya yaitu delay, jitter, packet loss dan throughput. Parameter tersebutlah yang digunakan untuk melakukan pengujian Quality of Service pada jaringan VoIP dalam pelaksanaan Tugas Akhir ini. Pengujian ini menggunakan aplikasi Wireshark dengan cara menyambungkan Laptop pada jaringan internet yang digunakan oleh user VoIP, kemudian menangkap setiap paket pada komunikasi user tersebut. Hasil pengujian delay, jitter dan packet loss didapatkan hasil seperti pada tabel 7 berikut.

Tabel 7. Hasil pengujian delay, jitter, packet loss dan throughput.

\begin{tabular}{|c|c|c|c|c|c|c|}
\hline Jenis & & & cobaa & ke & & Rat \\
\hline $\begin{array}{l}\text { Peng } \\
\text { ujian }\end{array}$ & 1 & 2 & 3 & 4 & 5 & $\begin{array}{c}\text { a- } \\
\text { rata }\end{array}$ \\
\hline Delay & 4,36 & 4,86 & 6,82 & 5,12 & 5,75 & 5,38 \\
\hline (ms) & 999 & 689 & 094 & 673 & 654 & 8218 \\
\hline Jitter & 2,47 & 1,79 & 8,79 & 6,46 & 6,21 & 5,14 \\
\hline$(m s)$ & 5 & 2 & 0 & 3 & 3 & 66 \\
\hline $\begin{array}{l}\text { Packe } \\
\text { t loss } \\
(\%)\end{array}$ & 0,9 & 0,0 & 0,2 & 0,2 & 0,5 & 0,36 \\
\hline $\begin{array}{l}\text { Throu } \\
\text { ghput } \\
\text { (bps) }\end{array}$ & $\begin{array}{l}136 \\
7\end{array}$ & 752 & 610 & 778 & 828 & 867 \\
\hline
\end{tabular}

Tabel 7 adalah hasil pengujian yang dilakukan dalam lima kali pengujian. Pada pengujian delay, didapatkan hasil 5,388218 ms, hasil tersebut menandakan bahwa hasil pengujian delay terbilang terbaik/ best. Kemudian pada pengujian jitter, dari lima kali pengujian, menghasilkan angka rata-rata jitter $5,1466 \mathrm{~ms}$, hasil tersebut dikatakan baik. Lalu untuk pengujian packet loss, hasil yang didapat adalah $0,36 \%$, hasil tersebut dikategorikan baik. Kemudian untuk rata-rata throughput yang dihasilkan adalah sebesar 867 bps. Dari hasil pengujian sebanyak lima kali tersebut, dapat diambil kesimpulan bahwa komunikasi pada jaringan VoIP dikategorikan baik.

\section{PENUTUP}

Hasil dari pelaksanaan Tugas Akhir ini adalah sebuah jaringan VoIP yang dapat digunakan untuk seluruh OPD Boyolali yang berfungsi untuk berkomunikasi antar instansi dilingkungan OPD Boyolali, sehingga mempermudah dan mempercepat komunikasi antar instansi di OPD Boyolali yang dapat meningkatkan kualitas pelayanan publik dan sistem pelaporan kerja pada OPD Boyolali. Jaringan VoIP ini juga mampu untuk menghemat pengeluran keuangan pada setiap OPD, karena setiap OPD tidak perlu membayar biaya untuk berlangganan jasa telepon, karena jaringan VoIP ini berjalan pada jaringan internet sehingga setiap OPD hanya perlu membayar biaya untuk berlangganan jasa internet saja. Dari hasil pengujian Quality of Service sebanyak lima kali yang menguji parameter delay, jitter dan packet loss tersebut, dapat diambil kesimpulan bahwa komunikasi pada jaringan VoIP dikategorikan baik.

Penulis berharap untuk kedepannya semoga jaringan VoIP ini dapat menjadi lebih besar dan dapat digunakan oleh semua masyarakat Boyolali untuk saling berkomunikasi. Penulis juga berharap semoga jaringan VoIP seperti ini dapat diaplikasikan pada OPD-OPD Daerah lain, agar dapat menghemat biaya dan mempermudah komunikasi pada OPD tersebut.

\section{DAFTAR PUSTAKA}

ETSI. (1998). Telecommunications and Internet Protocol Harmonization Over Networks (TIPHON); General aspects of Quality of Service (QoS). France: European Telecommunications Standards Institute.

H, M. Iskandarsyah. (2003). Dasar-Dasar Jaringan VOIP. IlmuKomputer.Com.

Nurhayati, O. D. (2010). Sistem Komunikasi Multimedia. eprint.undip.ac.id. (diakses pada tanggal 5 April 2018, pukul 9:36 WIB). 
Oladipo, F. O., Madu, C. C., \& Okoro, C. C. (2015). Re-Engineering Campus-Wide Internet Telephony Using Voice over Internet Protocol. International Journal of Networks and Communications, 23-30.

Prasetyo, E. (2015). Implementasi VoIP (Voice over Internet Protokol) pada Jaringan LAN (Local Area Network) Dinas Kesehatan Kabupaten Musi Banyuasin. Jurnal Teknik Informatika Politeknik Sekayu (TIPS), 19 - 27.

Saputra, E., \& Lestari, I. (2014). Analisa dan Perancangan Voice over Internet Protokol (VoIP) Menggunakan Teknologi Open Source pada Pusat Teknologi Informasi dan Pangkalan Data UIN Suska Riau. Jurnal Sains, Teknologi dan Industri, 106 - 111.

Sonnie Bestian, M., \& Rakhmadi, Aris (2011). Analisa Kinerja Voip Dan Video Conference Menggunakan Briker Softswitch Pada Jaringan Universitas Muhammadiyah Surakarta. eprint.ums.ac.id (diakses pada tanggal 27 Maret 2018, pukul 18:29 WIB). 